\section{BRAZIULIAN JOURNAL \\ OF MEDICAL AND BIOLOGICAL RESF.ARCH}

www.bjournal.com.br
ISSN 0100-879X

Volume 42 (12) 1119-1247 December 2009

BIOMEDICAL SCIENCES

AND

CLINICAL INVESTIGATION

Braz J Med Biol Res, December 2009, Volume 42(12) 1150-1155

Collagen XVIII/endostatin expression in experimental endotoxemic acute renal failure

M.C. Cichy, F.G.G. Rocha, V.R. Tristão, E.A. Pessoa, M.A. Cenedeze, R. Nürmberg Junior, N. Schor and M.H. Bellini

The Brazilian Journal of Medical and Biological Research is partially financed by
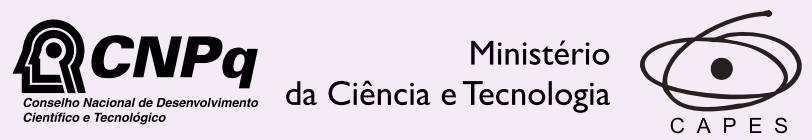

Ministério da Educação
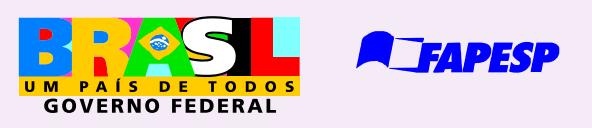

Institutional Sponsors 


\title{
Collagen XVIII/endostatin expression in experimental endotoxemic acute renal failure
}

\author{
M.C. Cichy¹, F.G.G. Rocha1 , V.R. Tristão1, E.A. Pessoa1, M.A. Cenedeze1, \\ R. Nürmberg Junior ${ }^{3}$, N. Schor ${ }^{1}$ and M.H. Bellini ${ }^{1,2}$ \\ ${ }^{1}$ Departamento de Medicina (Nefrologia), Escola Paulista de Medicina, \\ Universidade Federal de São Paulo, São Paulo, SP, Brasil \\ ${ }^{2}$ Centro de Biotecnologia, Instituto de Pesquisas Energéticas e Nucleares, São Paulo, SP, Brasil \\ ${ }^{3}$ Faculdade de Medicina Veterinária, Faculdades Metropolitanas Unidas, São Paulo, SP, Brasil
}

\begin{abstract}
Acute renal failure (ARF) is a frequent complication of Gram-negative sepsis, with a high risk of mortality. Lipopolysaccharide (LPS)-induced ARF is associated with hemodynamic changes that are strongly influenced by the overproduction of nitric oxide (NO) through the cytokine-mediated up-regulation of inducible NO synthase. LPS-induced reductions in systemic vascular resistance paradoxically culminate in renal vasoconstriction. Collagen XVIII is an important component of the extracellular matrix expressed in basement membranes. Its degradation by matrix metalloproteases, cathepsins and elastases results in the formation of endostatin, claimed to have antiangiogenic activity and to be a prominent vasorelaxing agent. We evaluated the expression of endostatin/collagen XVIII in an endotoxemic ARF model. ARF was induced in C57BL/6 mice by intraperitoneal injection of LPS $(10 \mathrm{mg} / \mathrm{kg})$ followed by sacrifice 4 and $12 \mathrm{~h}$ later. Kidney tissue was the source of RNA and protein and the subject of histological analysis. As early as $4 \mathrm{~h}$ after LPS administration, blood urea, creatinine and NO levels were significantly increased compared to control. Endostatin/collagen XVIII mRNA levels were 0.71 times lower than sham-inoculated mice $4 \mathrm{~h}$ after LPS inoculation, returning to normal levels $12 \mathrm{~h}$ after LPS inoculation. Immunohistological examination revealed that acute injury caused by LPS leads to an increase of endostatin basement membrane staining in association with the decrease of CD31 endothelial basement membrane staining. These results indicate that in the early phase of endotoxemic ARF the endostatin levels were not regulated by gene expression, but by the metabolism of collagen XVIII.
\end{abstract}

Key words: Acute renal failure; Lipopolysaccharide; Gene expression; Endostatin; CD31

\section{Introduction}

Acute renal failure (ARF) due to endotoxins is a common problem in clinical medicine. Endotoxins are released from the outer membrane of the Gram-negative bacterial envelope and are composed of lipopolysaccharides (LPS). ARF occurs in $20 \%$ of patients with severe sepsis and in $50 \%$ of patients with septic shock (1) and is clinically defined as a deterioration of glomerular filtration rate (GFR) and tubular function (2). Endotoxemia causes systemic release of cytokines $(3,4)$ as well as the overproduction of nitric oxide (NO) through the cytokine-mediated upregulation of inducible NO synthase (iNOS) (5-7).

Septic shock is characterized by generalized systemic vasodilation and hypotension accompanied by vascular hyporesponsiveness, leading to multiple organ failure and death $(8,9)$. Although systemic hypotension is often present, LPS-induced ARF is characterized by marked intrarenal vasoconstriction $(10,11)$. These hemodynamic changes alter renal blood flow, intrarenal hemodynamics and GFR. Intravital videomicroscopy has revealed that changes in peritubular capillaries can have a major impact on renal function (12). In fact, Wu et al. (12) demonstrated in a mouse model of endotoxemic ARF that renal peritubular capillary perfusion was significantly compromised as early as $2 \mathrm{~h}$ after LPS administration.

Collagen XVIII, a member of the heparan sulfate proteoglycan family, is an extracellular matrix (ECM) protein associated with basement membranes that is found in the basal laminae of the retina, epidermis, pia, heart and skeletal muscle, kidney, lung, and endothelial cells (13-15). Collagen XVIII molecules contain 10 triple-

Correspondence: M.H. Bellini, Instituto de Pesquisas Energéticas e Nucleares, Av. Lineu Prestes, 2242, 05508-000 São Paulo, SP, Brasil. Fax: +55-11-3812-3546. E-mail: mbmarumo@ipen.br

Received April 6, 2009. Accepted October 27, 2009. Available online November 6, 2009. Published December 4, 2009. 
helical collagenous domains that are separated and flanked by 11 non-triple-helical noncollagenous domains (NC). The NC1 region contains three functionally distinct regions: an association domain (necessary for collagen XVIII oligomerization), a hinge domain (sensitive to protease cleavage), and the endostatin domain (a 20-kDa fragment with potent antiangiogenic properties) (14-16). The proteolytic processing of collagen XVIII generates several C-terminal fragments ranging from 22 to $32 \mathrm{kDa}$ $(17,18)$.

Endostatin is the C-terminal fragment of collagen XVIII generated by proteolytic cleavage by proteases or metalloproteases (MMPs) such as cathepsin L, elastase or matricillin. After the proteolytic process, the generated endostatin can remain associated with the basement membrane (immobilized) or be released into the circulation (soluble endostatin). It has been shown in vitro that the soluble and the immobilized forms have distinct biological activities (19-25).

In the kidney, the entire outer surface of each nephron and collecting duct is covered by a basement membrane composed primarily of laminin, collagen IV, entactin/nidogen and heparan sulfate proteoglycans, with the last category containing collagen XVIII/endostatin $(21,22)$. The basement membrane plays an important role in the kidney since it is involved in the filtration process, as well as in cell adhesion, migration and differentiation.

During embryonic development, the presence of collagen XVIII has been detected in several organs, especially the kidneys, during the development of the ureteric bud (24). Karihaloo et al. (24) observed that specific degradation of collagen XVIII present in the basement membrane results in the accumulation of endostatin, which seems to exert local regulatory inhibition of the ureteric bud, preventing its branching. Karumanchi et al. (25) confirmed that endostatin binds to renal epithelial cells, showing an affinity pattern similar to that of endothelial cells.

In the adult kidney, collagen XVIII is widely distributed within the basement membrane. Immunohistochemical analyses have emphasized its presence in the intertubular (continued) as well as in the specialized (glomerular) capillaries (26). The endostatin found in extracts of kidney, liver, brain, heart and testes varies from 0.3 to $2 \mu \mathrm{g} / \mathrm{mL}$. These values are at least ten times higher than those found in the circulation (19).

We recently reported the presence and up-regulation of endostatin mRNA and protein in a mouse model of ischemia-reperfusion injury and obstructive nephropathy $(18,27)$. The role of endostatin in renal disease is not clear; however, our data indicate that this molecule, together with angiogenic factors, participates in the endothelial response to renal injury.

The purpose of the present study was to examine the expression of kidney endostatin in the early phase of LPSinduced endotoxemic ARF.

\section{Material and Methods}

\section{Animals}

Experiments were conducted on adult C57BL/6 mice (2 to 4 months old, $22-28 \mathrm{~g}$ body weight) maintained under specific pathogen-free conditions at the National Pharmacology Institute, Federal University of São Paulo, São Paulo, $\mathrm{SP}$, Brazil. The experimental procedure was approved by the Federal University of São Paulo Committee for the Use of Live Animals in Teaching and Research.

\section{ARF model}

Mice were injected intraperitoneally with $10 \mathrm{mg} / \mathrm{kg}$ Escherichia coli LPS serotype 0111:B4 (Sigma-Aldrich, USA). At 4 and $12 \mathrm{~h}$, respectively, after LPS inoculation the animals were anesthetized with ketamine $(125 \mathrm{mg} / \mathrm{g}$ body weight, Ketalar; Parke-Davis, USA) and xylazine $(12.5 \mathrm{mg} / \mathrm{g}$ body weight; Phoenix Scientific, Inc., USA), and blood was collected via the orbital sinus. This procedure was followed immediately by cervical dislocation and kidney harvest. One kidney was snap-frozen in liquid nitrogen and used for protein and total RNA extraction, and the other was fixed in $10 \%$ phosphate-buffered formalin for immunohistochemistry, and also stained with hematoxylin-eosin and periodic acid-Schiff.

\section{Chemicals and renal function}

Approximately $0.2 \mathrm{~mL}$ blood was collected from each animal into EDTA used as an anticoagulant.

Blood urea nitrogen and plasma creatinine levels were determined using commercial kits (Urea UV Liquiform, Cat. 104, and Creatinine K, Cat. 96, respectively; Labtest Diagnostics, Brazil).

Serum nitrate/nitrite (NOx) levels were determined by the Griess test. Briefly, serum samples diluted in water were deproteinized by treatment with $1.84 \%$ sulfuric acid (1:1 dilution), $10 \%$ sodium tungstate (1:1), and deionized water (2:1). The samples were then centrifuged at $2000 \mathrm{~g}$ for $10 \mathrm{~min}$ and the supernatants were collected. Nitrite levels were estimated in the supernatants using the Griess reagent [equal volumes of a solution of $1 \%$ sulfanilamide- $0.8 \%$ $\mathrm{N}$-(1-naphthyl)-ethylenediamine in water and $0.5 \mathrm{~N} \mathrm{HCl}$. After 20 min of incubation at room temperature (28), test and standard curve absorbance were read at $550 \mathrm{~nm}$. The results were compared against an $\mathrm{NaNO}_{2}$ standard curve, and the nitrite concentration $(\mu \mathrm{M})$ was calculated.

\section{Quantitative real-time polymerase chain reaction}

The reverse transcription polymerase chain reaction (RT-PCR) was performed for endostatin in RNA extracted from the kidneys of normal and ARF mice at 4 and $12 \mathrm{~h}$ after injection of $10 \mathrm{mg} / \mathrm{kg}$ LPS. Total RNA was harvested from the renal tissue using the Trizol reagent (Life Technologies, USA). Total RNA samples of $2 \mu \mathrm{g}$ were used to accurately detect changes in the number of endostatin 
gene copies. The target gene expression was normalized to hypoxanthine-guanine phosphoribosyltransferase (HPRT) levels. The primer for mouse endostatin was Mm00487129_m1 (TaqMan ${ }^{\circledR}$ Gene Expression Assays, Applied Biosystems, USA) and the primer for mouse HPRT was Mm03024075_m1 (TaqMan ${ }^{\circledR}$ Gene Expression Assays, Applied Biosystems). Quantitative RT-PCR was carried out in a thermocycler (7300 Real-Time PCR System; Applied Biosystems) using TaqMan ${ }^{\circledR}$ Gene Expression Master Mix (Applied Biosystems) according to manufacturer recommendations (29). Relative quantification was performed to describe the change in endostatin expression in LPS-treated mice compared to untreated controls.

\section{Western blot analysis}

Kidneys harvested from normal and ARF mice were homogenized in warmed protein extraction buffer $(0.1 \mathrm{M}$ Tris, $0.01 \mathrm{M}$ EDTA, $1 \% \mathrm{SDS}$, and $0.01 \mathrm{M} \mathrm{DTT}, \mathrm{pH} 8.0$ ). After $2 \mathrm{~min}$ of incubation at $95^{\circ} \mathrm{C}$, the homogenate was centrifuged at $13,000 \mathrm{rpm}$ for $15 \mathrm{~min}$ and the supernatant was stored at $-80^{\circ} \mathrm{C}$. The samples $(50 \mu \mathrm{g}$ protein per lane $)$ were run under reducing conditions on sodium dodecyl sulfate-polyacrylamide gels ( $4 \%$ stacking gel, $12 \%$ separating gel). The gels were then electroblotted onto nitrocellulose membranes. After blocking, the blots were incubated overnight with a rabbit anti-mouse endostatin polyclonal antibody (work dilution 1:100, Chemicon International, USA) and a horseradish peroxidase-conjugated goat anti-rabbit antibody as the secondary antibody (work dilution 1:2000, Chemicon International, USA). Bands were detected using enhanced chemiluminescence system (Amersham Bioscience, USA) according to manufacturer guidelines.

\section{Immunohistochemical staining}

Immunohistochemical analyses were performed at the University of São Paulo School of Medicine. Paraffinembedded sections of mouse kidneys (4- $\mu \mathrm{m}$ thick) were mounted onto SuperFrost Plus slides (Fisher Scientific, USA), baked, deparaffinized and rehydrated. Heat-induced epitope retrieval was performed by immersion of the slides in $1 \mathrm{mM}$ EDTA, pH 8.0, and incubation in an electric pressure cooker (Decloaking Chamber; BioCare Medical, USA) for 3 $\mathrm{min}$ at $25 \mathrm{psi}$. The slides were then placed in an automated immunohistochemical stainer (Ventana Medical Systems, USA) for endostatin staining. Endostatin labeling was performed using the $\mathrm{Cl} 1837.46$ monoclonal antibody (Upstate Biotechnology, USA) at $1: 100$ dilution for $28 \mathrm{~min}$ at $42^{\circ} \mathrm{C}$, an amplification kit and a basic diaminobenzidine detection system (Dako, USA). CD31 labeling was performed using a monoclonal antibody (Chemicon International, USA) at 1:50 dilution for $28 \mathrm{~min}$ at $42^{\circ} \mathrm{C}$, following the same procedure as described above. The images were obtained with a digital camera (DXM1200F; Nikon Instruments Inc., USA) and analyzed using the EclipseNet software.

\section{Statistical analysis}

Statistical analysis of the experimental groups was performed using the Student $t$-test with the level of significance set at $\mathrm{P}<0.05$. Data are reported as mean \pm SD.

\section{Results}

\section{Renal function}

LPS induced significant renal failure, as shown by the approximate doubling of plasma creatinine (normal: $1.14 \pm$ $0.3 ; 4 \mathrm{h:} 2.16 \pm 0.2 ; 12 \mathrm{~h}: 3.44 \pm 0.3$ ) and blood urea nitrogen (normal: $35.1 \pm 4 ; 4$ h: $84 \pm 11.1$; 12 h: $153.5 \pm 24.5$ ) levels compared to normal mouse values $(P<0.01)$. Renal histology revealed mild morphological damage, including tubular dilatation and loss of brush border (Figure 1A and B).

\section{Serum NOx levels}

LPS is known to induce iNOS and to increase systemic NO synthesis. Serum NOx, which are NO metabolites,
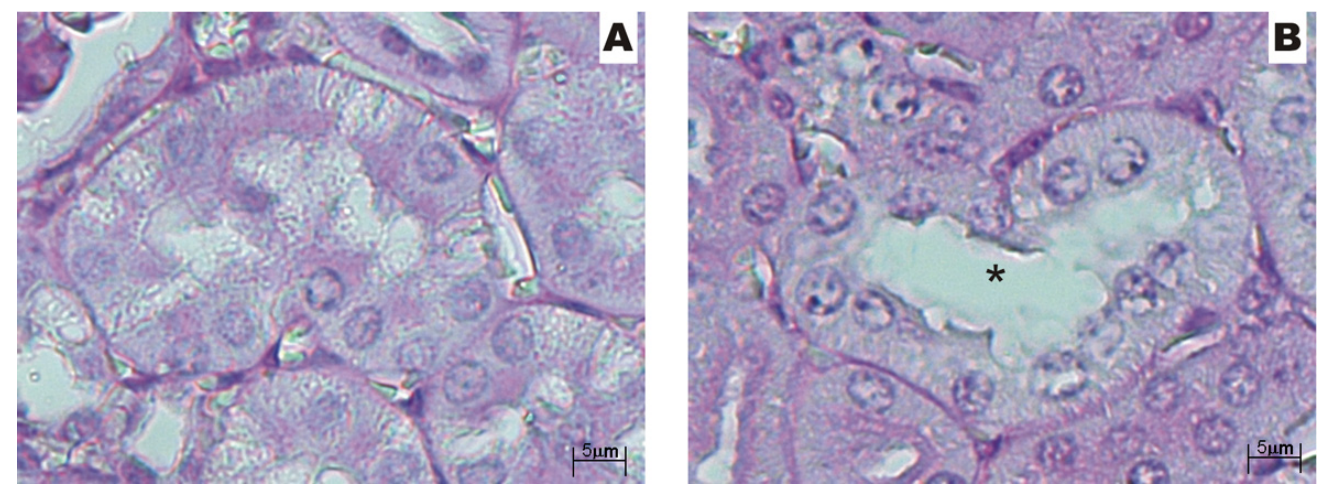

Figure 1. Histopathological findings obtained by light microscopy for normal and lipopolysaccharide (LPS)-injured kidney (100 mg/kg). $A$, Tubules from normal mice; $B$, tubules from LPS-injured kidney - tubular dilatation (asterisk). Staining: hematoxylin-eosin; original magnification: $40 \mathrm{X}$. 
indicate NO generation. The NOx levels were significantly elevated 4 and $12 \mathrm{~h}$ after LPS administration. At $4 \mathrm{~h}, \mathrm{NOx}$ levels showed a 10 -fold increase from $45 \pm 6 \mu \mathrm{M}(\mathrm{N}=4)$ in the control group to $425 \pm 83 \mu \mathrm{M}(\mathrm{N}=4)$ in the LPS group $(P<0.001)$. At $12 \mathrm{~h}, \mathrm{NOx}$ levels were decreased $(325 \pm 12$ $\mu \mathrm{M})$, but significantly higher than in the control group.
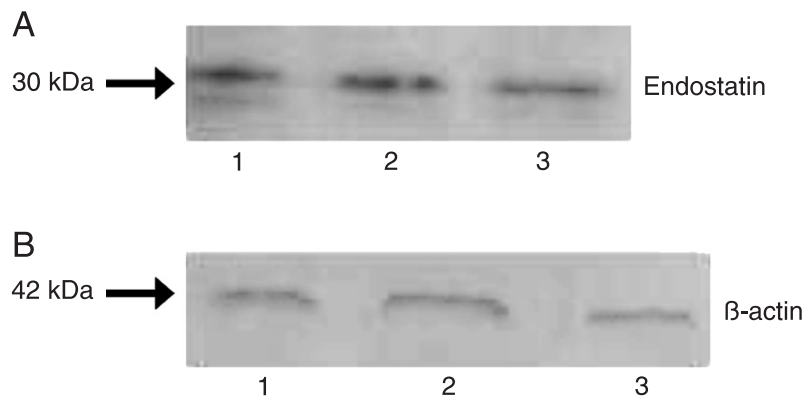

Figure 2. Expression of endostatin in normal and LPS-injured kidneys demonstrated by Western blot analysis. A, Endostatin analysis: normal kidney (lane 1); kidneys at 4 and $12 \mathrm{~h}$ after LPS administration (lanes 2 and 3 , respectively); $B, \beta$-actin analysis in the same kidney samples.

\section{Quantitative RT-PCR}

After $4 \mathrm{~h}$ of LPS treatment, endostatin mRNA level was down-regulated $(0.18 \pm 0.15)$. At the end of 12-h treatment, endostatin mRNA level returned to normal $(0.91 \pm 0.21)$.

There was a significant decrease of endostatin mRNA levels at $4 \mathrm{~h}$ after LPS treatment (0.71 times lower than the levels of sham-inoculated mice; $P<0.01)$. Of interest, the signals of endostatin mRNA were not significantly changed in the normal mice kidneys.

\section{Western blot analysis}

Endostatin levels, examined by Western blot (Figure 2), were stable at $4 \mathrm{~h}(1.95 \pm 0.12)$ after LPS treatment and at $12 \mathrm{~h}$ they were significantly reduced $(1.7 \pm 0.13)$ compared to the control group $(1.8 \pm 0.3 ; \mathrm{P}<0.05)$.

\section{Immunohistochemistry analysis}

Figure 3 shows the results of immunostaining for endostatin in normal and LPS-treated kidneys. In the normal kidney cells, we observed a diffuse staining for endostatin in the proximal and distal tubules; endostatin staining was positive in the basement membrane of Bowman's capsule and in the glomerular capillaries (Figure 3A). Four hours after LPS treatment, the kidney showed marked staining
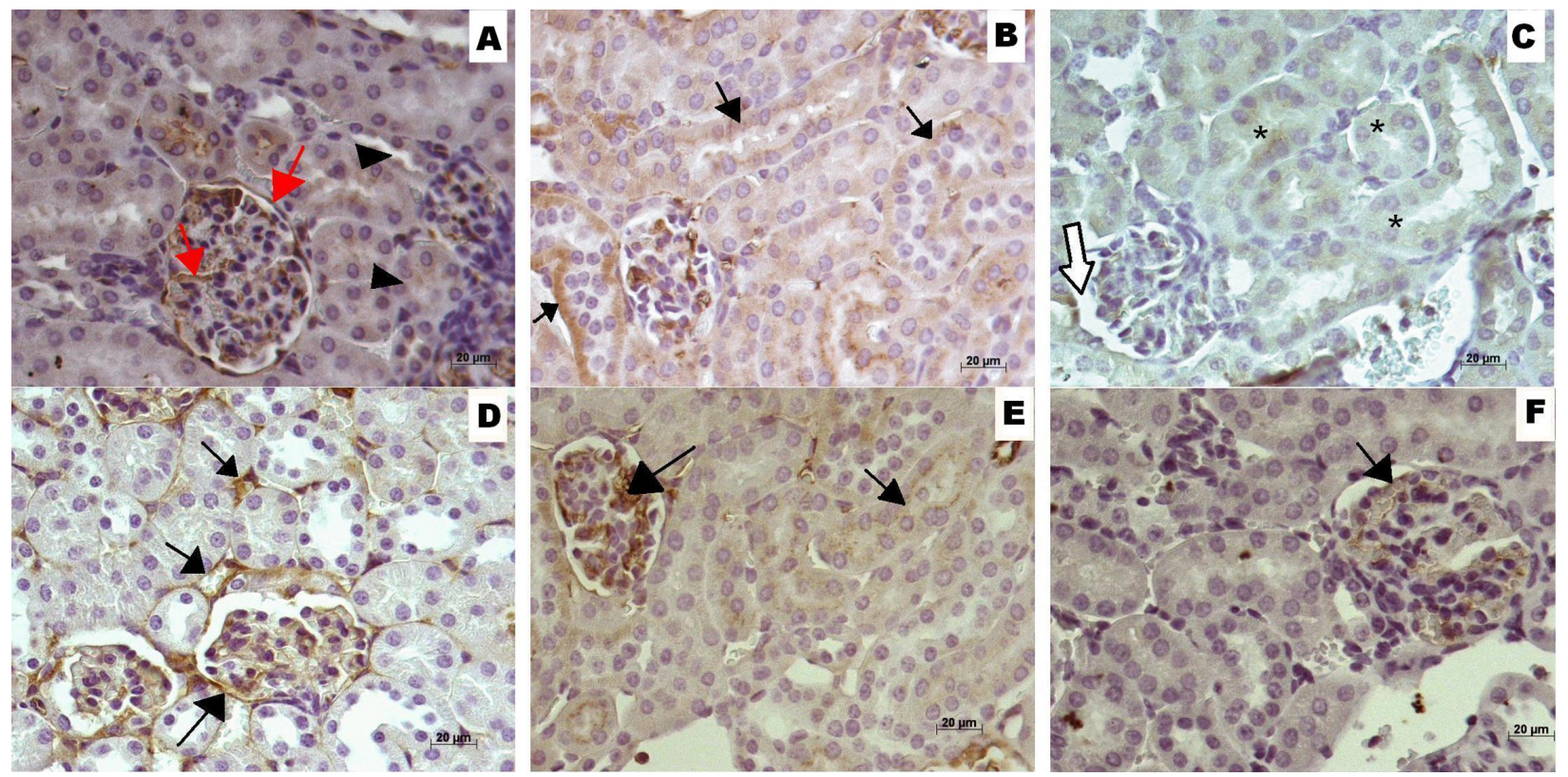

Figure 3. Immunohistochemical staining for endostatin and CD31, in normal ( $A$ and $D)$ and endotoxemic (B, C, E, and F) mouse kidneys. $A$, Diffuse cytoplasmic staining for endostatin in proximal and distal tubules (arrowheads); endostatin staining is positive in the basement membrane of Bowman's capsule and in endothelial cells of the glomerular capillaries (red arrow); $B$, kidney $4 \mathrm{~h}$ after LPS inoculation showing strong staining of the tubular basement membranes (arrows); $C$, kidney $12 \mathrm{~h}$ after LPS inoculation showing moderate staining for endostatin in proximal and distal tubules (asterisks) and in a glomerulus (thick arrow); $D$, CD31-positive in peritubular arterioles, in the basement membrane of Bowman's capsule and in glomerular endothelial cells (arrows); $E$, kidney $4 \mathrm{~h}$ after LPS inoculation showing moderate and diffuse staining of tubular cells (arrows); $F$, kidney $12 \mathrm{~h}$ after LPS inoculation showing minimal tubular and glomerular (arrow) staining. Magnification: 40X. 
Table 1. Effect of lipopolysaccharides on immunohistochemical staining of endostatin and CD31 expression.

\begin{tabular}{ccc}
\hline Animal group $(\mathrm{N}=4)$ & Endostatin & CD31 \\
\hline Sham & ++ & +++ \\
$4 \mathrm{~h}$ & +++ & ++ \\
$12 \mathrm{~h}$ & $++/+++$ & $0 /+$ \\
\hline
\end{tabular}

Expression of endostatin and CD31 was scored by a blinded independent pathologist as: rare $(0)$, minimal $(+)$, moderate $(++)$, and intense (+++). Four samples were processed for analysis.

in the tubular basement membranes (Figure 3B) and 12 $\mathrm{h}$ after LPS treatment a reduction in staining was evident (Figure $3 \mathrm{C}$ ), with moderate to weak staining of tubules and glomeruli.

Immunohistochemical staining for CD31 revealed a progressive decrease of kidney endothelial CD31 expression (Figure 3D-F). As early as $4 \mathrm{~h}$ after LPS administration, the peritubular endothelial cells showed a decrease in the expression of CD31, while CD31 expression was unchanged in the glomerular endothelium (Figure 3E). Twelve hours after LPS inoculation, CD31 expression virtually disappeared (Figure 3F).

Semi-quantitative analysis of endostatin and CD31 expression in normal and endotoxemic kidneys demonstrated an opposite modulation by LPS. There was an increase in focal expression of endostatin and marked decrease in CD31 expression in both the tubular and glomerular endothelium (Table 1).

\section{Discussion}

LPS-induced ARF is associated with hemodynamic changes that are strongly influenced by NO overproduction through the cytokine-mediated up-regulation of iNOS (5-7). These hemodynamic changes alter renal blood flow, intrarenal hemodynamics, and GFR and produce marked intrarenal vasoconstriction $(10,11)$.

In a previous study, using a murine model of ischemia/ reperfusion-induced and obstructive nephropathy, we reported that collagen $\mathrm{XVIII/endostatin} \mathrm{takes} \mathrm{part} \mathrm{in} \mathrm{the}$ physiopathology of ischemic ARF, as well as in a fibrotic process $(18,27)$.

In the present study, we used an experimental endotoxemic animal model in order to analyze the expression of collagen XVIII/endostatin in the early phase of endotoxemic ARF.

Our results demonstrate that LPS injury caused a significant but transient decrease in endostatin mRNA levels $4 \mathrm{~h}$ after LPS treatment. This transient decrease had no marked reflection on protein levels. These data demonstrate that the endostatin detected by Western blot analysis and immunohistology is a product of collagen XVIII cleavage, which in turn indicates that, in the early phase of endotoxemic ARF, the increase in endostatin is a consequence of collagen metabolism. This is consistent with studies showing the anti-angiogenic activity of noncollagenous domain proteolytic fragments of collagen types XVIII (endostatin) and XV (restin) and type IV collagen chains a1 (arrestin), a2 (canstatin), and a3 (tumstatin) $(22,30,31)$.

Metalloproteases and other proteases are involved in the cleavage of collagens and, consequently, in ECM remodeling, wound healing, development, cancer invasion, and angiogenesis $(19,20)$.

LPS-induced endotoxemia causes up-regulation of several MMP genes in the liver, spleen and kidney. The increased MMP activity present in the kidney might have a significant impact on the basement membrane components, including collagen XVIII degradation (25).

Immunostaining experiments have revealed an increase of endostatin on the basolateral tubular surface in association with a decreased number of positive endothelial cells, especially in the peritubular capillaries. Tiwari et al. (7), using intravital videomicroscopy, showed that peritubular capillary perfusion is dramatically reduced in the early phase of endotoxemic ARF. In an in vitro experiment, Yu et al. (31) demonstrated that LPS-activated endothelial cells were more endostatin-sensitive. HDMEC cells, upon activation by LPS or IL-1 $\beta$, displayed a dose-dependent sensitivity to endostatin.

The increased levels of endostatin may result from gene expression regulation and/or collagen XVIII cleavage. We reported previously that collagen XVIII/endostatin gene expression as well as endostatin levels were up-regulated in an ischemic ARF and obstructive nephropathy model $(18,27)$. These data demonstrated the presence of both genetic and metabolic control of collagen XVIII/endostatin in these nephropathy models.

The results of the present study indicate that in the early phase of endotoxemic ARF, the increased levels of renal endostatin were not associated with gene expression, but rather with the metabolism of collagen XVIII. These results could be explained by the LPS induction of major changes in the extracellular proteolytic balance of the murine kidney (32). Imbalanced extracellular proteolysis participates in the alterations of kidney function in septic shock, and we believe that endostatin release may play a role in the reduction of renal capillary density and, consequently, in the alterations of intrarenal hemodynamics.

\section{Acknowledgments}

Research supported by FAPESP (\#2007/51204-4). M.C. Cichy (\#2008/52652-3), F.G.G. Rocha (\#2008/52654-6), and E.A. Pessoa (\#2008/52613-8) are recipients of fellowships from FAPESP. V.R. Tristão is the recipient of a fellowship from CAPES. 


\section{References}

1. Schmidt C, Hocherl K, Schweda F, Kurtz A, Bucher M. Regulation of renal sodium transporters during severe inflammation. $J$ Am Soc Nephrol 2007; 18: 1072-1083.

2. Cunningham PN, Holers VM, Alexander JJ, Guthridge JM, Carroll MC, Quigg RJ. Complement is activated in kidney by endotoxin but does not cause the ensuing acute renal failure. Kidney Int 2000; 58: 1580-1587.

3. Singbartl K, Bockhorn SG, ZarbockA, Schmolke M, Van Aken H. $T$ cells modulate neutrophil-dependent acute renal failure during endotoxemia: critical role for CD28. J Am Soc Nephrol 2005; 16: 720-728.

4. Cunningham PN, Wang Y, Guo R, He G, Quigg RJ. Role of Toll-like receptor 4 in endotoxin-induced acute renal failure. $J$ Immunol 2004; 172: 2629-2635.

5. Wu L, Mayeux PR. Effects of the inducible nitric-oxide synthase inhibitor L-N(6)-(1-iminoethyl)-lysine on microcirculation and reactive nitrogen species generation in the kidney following lipopolysaccharide administration in mice. J Pharmacol Exp Ther 2007; 320: 1061-1067.

6. Zager RA, Johnson AC, Lund S, Hanson SY, Abrass CK. Levosimendan protects against experimental endotoxemic acute renal failure. Am J Physiol Renal Physiol 2006; 290: F1453-F1462.

7. Tiwari MM, Brock RW, Megyesi JK, Kaushal GP, Mayeux PR. Disruption of renal peritubular blood flow in lipopolysaccharideinduced renal failure: role of nitric oxide and caspases. Am J Physiol Renal Physiol 2005; 289: F1324-F1332.

8. Cunningham PN, Dyanov HM, Park P, Wang J, Newell KA, Quigg RJ. Acute renal failure in endotoxemia is caused by TNF acting directly on TNF receptor-1 in kidney. J Immunol 2002; 168 : 5817-5823.

9. Poole B, Wang W, Chen YC, Zolty E, Falk S, Mitra A, et al. Role of heme oxygenase-1 in endotoxemic acute renal failure. Am J Physiol Renal Physiol 2005; 289: F1382-F1385.

10. Boffa JJ, Arendshorst WJ. Maintenance of renal vascular reactivity contributes to acute renal failure during endotoxemic shock. $J$ Am Soc Nephrol 2005; 16: 117-124.

11. Yamaguchi N, Jesmin S, Zaedi S, Shimojo N, Maeda S, Gando $\mathrm{S}$, et al. Time-dependent expression of renal vaso-regulatory molecules in LPS-induced endotoxemia in rat. Peptides 2006; 27: 2258-2270

12. Wu L, Tiwari MM, Messer KJ, Holthoff JH, Gokden N, Brock RW, et al. Peritubular capillary dysfunction and renal tubular epithelial cell stress following lipopolysaccharide administration in mice. Am J Physiol Renal Physiol 2007; 292: F261-F268.

13. Saarela J, Rehn M, Oikarinen A, Autio-Harmainen H, Pihlajaniemi T. The short and long forms of type XVIII collagen show clear tissue specificities in their expression and location in basement membrane zones in humans. Am J Pathol 1998; 153: 611-626.

14. Halfter W, Dong S, Schurer B, Cole GJ. Collagen XVIII is a basement membrane heparan sulfate proteoglycan. J Biol Chem 1998; 273: 25404-25412.

15. Sasaki T, Fukai N, Mann K, Gohring W, Olsen BR, Timpl R. Structure, function and tissue forms of the C-terminal globular domain of collagen XVIII containing the angiogenesis inhibitor endostatin. EMBO J 1998; 17: 4249-4256.

16. O'Reilly MS, Boehm T, Shing Y, Fukai N, Vasios G, Lane WS, et al. Endostatin: an endogenous inhibitor of angiogenesis and tumor growth. Cell 1997; 88: 277-285.

17. Miosge N, Sasaki T, Timpl R. Angiogenesis inhibitor endostatin is a distinct component of elastic fibers in vessel walls. FASEB J 1999; 13: 1743-1750.

18. Maciel TT, Coutinho EL, Soares D, Achar E, Schor N, Bellini $\mathrm{MH}$. Endostatin, an antiangiogenic protein, is expressed in the unilateral ureteral obstruction mice model. J Nephrol 2008; 21: 753-760.

19. Felbor U, Dreier L, Bryant RA, Ploegh HL, Olsen BR, Mothes W. Secreted cathepsin $L$ generates endostatin from collagen XVIII. EMBO J 2000; 19: 1187-1194.

20. Lin HC, Chang JH, Jain S, Gabison EE, Kure T, Kato T, et al. Matrilysin cleavage of corneal collagen type XVIII NC1 domain and generation of a 28-kDa fragment. Invest Ophthalmol Vis Sci 2001; 42: 2517-2524.

21. Miner JH. Renal basement membrane components. Kidney Int 1999; 56: 2016-2024

22. Tomono Y, Naito I, Ando K, Yonezawa T, Sado Y, Hirakawa S, et al. Epitope-defined monoclonal antibodies against multiplexin collagens demonstrate that type XV and XVIII collagens are expressed in specialized basement membranes. Cell Struct Funct 2002; 27: 9-20.

23. Pagenstecher A, Stalder AK, Kincaid CL, Volk B, Campbell IL. Regulation of matrix metalloproteinases and their inhibitor genes in lipopolysaccharide-induced endotoxemia in mice. Am J Pathol 2000; 157: 197-210.

24. Karihaloo A, Karumanchi SA, Barasch J, Jha V, Nickel CH, Yang $\mathrm{J}$, et al. Endostatin regulates branching morphogenesis of renal epithelial cells and ureteric bud. Proc Natl Acad Sci U S A 2001; 98: 12509-12514.

25. Karumanchi SA, Jha V, Ramchandran R, Karihaloo A, Tsiokas L, Chan B, et al. Cell surface glypicans are low-affinity endostatin receptors. Mol Cell 2001; 7: 811-822.

26. Miosge N, Simniok T, Sprysch P, Herken R. The collagen type $\mathrm{XVIII}$ endostatin domain is co-localized with perlecan in basement membranes in vivo. $J$ Histochem Cytochem 2003; 51: 285-296.

27. Bellini MH, Coutinho EL, Filgueiras TC, Maciel TT, Schor N. Endostatin expression in the murine model of ischaemia/ reperfusion-induced acute renal failure. Nephrology 2007; 12: 459-465.

28. An HJ, Seo MJ, Choi IY, Park RK, Jeong S, Lee JY, et al. Induction of nitric oxide \& tumour necrosis factor-alpha by Psoralea corylifolia. Indian J Med Res 2008; 128: 752-758.

29. Lazaruk K, Wang Y, Zhong J, Maltchenko S, Rabkin S, Hunkapiller $\mathrm{K}$, et al. The design process for a new generation of quantitative gene expression analysis tools: TaqMan ${ }^{\circledR}$ Probe-based assays for human and other model organism genes. White Paper TaqMan ${ }^{\circledR}$ Gene Expression Assays [http://www3.appliedbiosystems.com/cms/groups/mcb_marketing/documents/ generaldocuments/cms_040599.pdf]; 2009.

30. Rehn M, Veikkola T, Kukk-Valdre E, Nakamura H, Ilmonen $\mathrm{M}$, Lombardo $\mathrm{C}$, et al. Interaction of endostatin with integrins implicated in angiogenesis. Proc Natl Acad Sci U S A 2001; 98: 1024-1029.

31. Yu Y, Moulton KS, Khan MK, Vineberg S, Boye E, Davis VM, et al. E-selectin is required for the antiangiogenic activity of endostatin. Proc Natl Acad Sci U S A 2004; 101: 8005-8010.

32. Moll S, Schifferli JA, Huarte J, Lemoine R, Vassalli JD, Sappino AP. LPS induces major changes in the extracellular proteolytic balance in the murine kidney. Kidney Int 1994; 45: 500-508. 